\title{
Ovulation following unilateral ovariectomy in the California leaf-nosed bat (Macrotus californicus)
}

\author{
W. J. Bleier and M. Ehteshami
}

Department of Zoology, North Dakota State University, Fargo, North Dakota 58105, U.S.A.

\begin{abstract}
Summary. Ovulation occurred from the left ovary in all 5 bats that had had the right ovary removed and an implanting blastocyst was found in the left uterine horn in 2 of these bats. All ovulations in the control and sham-operated bats occurred from the right ovary.
\end{abstract}

\section{Introduction}

The California leaf-nosed bat, Macrotus californicus, is in the New World family Phyllostomatidae. This insectivorous bat is distributed in lowland desert regions of the south-western United States and north-western Mexico. An unusual feature of its reproductive biology is the length of gestation. Adult bats weigh approximately $13 \mathrm{~g}$ and yet the gestation period is 8-9 months (Bradshaw, 1962; Bleier, 1975). This gestation period is considerably longer than would be expected for a mammal of this size. Although implantation begins immediately after the blastocyst enters the uterus, early fetal growth is slow so that the primitive streak stage is not reached until approximately the 5th month of gestation. Another unusual feature of this bat's reproductive biology is that ovulation is always from the right side only, although the left ovary appears morphologically normal when viewed by light microscopy.

This paper reports the response of the left ovary following contralateral ovariectomy.

\section{Materials and Methods}

California leaf-nosed bats (M. californicus) were captured on 10 August 1979 and brought back to the laboratory at Fargo, North Dakota. The bats were maintained in a wire cage in a room with an ambient temperature of approximately $25^{\circ} \mathrm{C}$. The room had 2 outside windows which allowed exposure of the bats to a natural light cycle. Food and water were provided ad libitum. Males and females were housed together in the same cage. To help ensure that the bats used in this study were reproductively normal, only females that had just finished lactating and hence had successfully completed pregnancy were used.

Approximately 2 weeks after capture laparotomies were performed on 8 bats. Individuals were anaesthetized with pentobarbitone sodium at a dosage of $43 \mathrm{mg} / \mathrm{kg}$. The right ovary was removed from 5 individuals; 3 sham operations were performed; and 5 intact bats served as controls.

In late October and early November (i.e. 8-10 weeks after operation) the bats were killed. The reproductive tracts were removed, fixed in formol-acetic acid-ethyl alcohol, embedded in paraffin wax, serially sectioned at $7 \mu \mathrm{m}$, and stained with haematoxylin and eosin. 


\section{Results}

All ovariectomized bats ovulated from the left ovary while all ovulations in the sham-operated and control groups were from the right ovary (Table 1). Two ovariectomized individuals had an implanting blastocyst in the left uterine horn and another ovariectomized individual had an atretic ovum in the ampulla. Two of the ovariectomized females had ovulated (as indicated by the presence of a corpus luteum in the left ovary), but no trace of an egg or embryo was found in the oviduct or uterus.

Table 1. Ovarian activity in control, sham-operated and ovariectomized California leaf-nosed bats

\begin{tabular}{lccc}
\hline & Control $^{*}$ & Sham $^{*}$ & Ovariectomy $\dagger$ \\
\hline No ovulation & 2 & 0 & 0 \\
Ovulation (non-pregnant) & 2 & 1 & 3 \\
Ovulation (pregnant) & 1 & 2 & 2 \\
\hline
\end{tabular}

* Ovulation was from the right ovary.

† Ovulation was from the left ovary.

Each sham-operated female had ovulated. One individual had a corpus luteum in the right ovary, although no egg or embryo was observed in the oviduct or uterus and the other 2 each had an implanting blastocyst in the right uterine horn.

Of the control bats 2 had not ovulated: one had follicular development to the secondary stage in both ovaries, while the other had a large vesicular follicle in the right ovary and numerous secondary follicles in both ovaries. Of the control bats that had ovulated, one had an implanting blastocyst in the right uterine horn, one had an atretic ovum in the ampulla of the right oviduct and the third had a corpus luteum in the right ovary but no trace of the egg in the oviduct or uterus.

\section{Discussion}

Unilateral ovulation has been reported in a number of bats (for review, see Wimsatt, 1979). Miniopterus dasythrix ovulates from the left ovary only, even though the right ovary appears normal (Matthews, 1942), and ovulation in Megaderma lyra is predominantly from the left ovary (Ramaswamy, 1961). Ovulation occurs only from the right ovary in Rhinolophus ferrum-equinum (Matthews, 1937) and Tadarida braziliensis cynocephala (Sherman, 1937). In Miniopterus schreibersii ovulation is almost invariably from the right ovary (Courrier, 1927).

A pattern of ovulation similar to that of $M$. californicus was reported in the South American rodent, the mountain viscacha, which almost always ovulates from the right ovary; removal of this ovary results in contralateral ovulation and embryonic development (Pearson, 1949). The reasons for the unilateral ovulation in the above species have not been determined.

The present investigation demonstrates that the left ovary is capable of ovulation and development of a corpus luteum if the right ovary is removed. Also, if fertilized, an ovum from the left ovary is capable of development to at least the implanting blastocyst stage. Moreover, this development occurs in the left uterine horn, whereas, under normal conditions implantation and subsequent development is always in the right uterine horn. In parous females the right uterine horn is larger than the left. Thus, the right uterine horn is apparently dominant; however, migration of an egg from the left to the right side is not necessary for development to at least the stage of an implanting blastocyst.

Our observations show that the left ovary apparently has the potential to function normally if the right ovary is removed. In one of the control bats that had not ovulated, the right ovary 
had a large vesicular follicle, while the left ovary had large secondary follicles but no vesicular follicles. We suggest that the follicular maturation in the left ovary lags behind that of the contralateral side and hence ovulation occurs from the right ovary. The cause of this lag in development of the left ovary is unknown.

We thank Laurie Smestad for technical assistance and Charlotte Meester for typing this manuscript.

\section{References}

Bleier, W.J. (1975) Early embryology and implantation in the California leaf-nosed bat, Macrotus californicus. Anat. Rec. 182, 237-254.

Bradshaw, G.V.R. (1962) Reproductive cycle of the California leaf-nosed bat, Macrotus californicus. Science, N.Y. 136, 645-646.

Courrier, R. (1927) Étude sur le determinisme caractères sexuels secondaires chez quelques mammifëres a activité testiculaire periodique. Archs Biol. 37, 173-334.

Matthews, L.H. (1937) The female sexual cycle in the British horse-shoe bats, Rhinolophus ferrumequinum insulanus Barrett-Hamilton and $R$. hipposideros minutus Montaga. Trans. Zool. Soc. Lond. 23, 213-255.
Matthews, L.H. (1942) Notes on the genitalia and reproduction of some African bats. Proc. Zool. Soc. Lond. B, 111, 289-346.

Pearson, O.P. (1949) Reproduction of a South American rodent, the mountain viscacha. Am. J. Anat. 84, 143-173.

Ramaswamy, K.R. (1961) Studies on the sex cycle of the Indian vampire bat, Megaderma (Lyroderma) lyra lyra (Geoffroy). Part I. Breeding habits. Proc. Nat. Inst. Sci. India, Sect. B 27, 287-307.

Sherman, H.B. (1937) Breeding habits of the free-tailed bat. J. Mammal. 18, 176-187.

Wimsatt, W.A. (1979) Reproductive asymmetry and unilateral pregnancy in Chiraptera. $J$. Reprod. Fert. 56, 345-357. 